\title{
Circulação e vazão de água em encosta com erosão em túneis na bacia do rio das pombas - Guarapuava - PR
}

\author{
Movimiento y flujo de erosión de agua pendiente con túnel en \\ la cuenca del río de palomas - Guarapuava - PR
}

\section{Routes of movement and flow of water systems in slopes with erosion in tunnels of the basin of the river pombas - Guarapuava - PR}

\author{
Wellington Barbosa Silva \\ w_barbosa@hotmail.com \\ Universidade Federal de Santa Catarina
}

Gisele Pietrobelli

gipietrobelli@hotmail.com

Universidade Estadual do Centro Oeste

Eliza Belem Tratz
elizatratz@gmail.com

Universidade Federal de Santa Catarina

\begin{abstract}
Resumo: A formação de túneis evidencia relação direta com infiltração e percolação de água na encosta. A água que infiltra no solo tende naturalmente a percorrer o caminho favorecido pela gravidade, de acordo com a energia potencial adquirida pela declividade da encosta. A proposta deste trabalho foi de reconhecer a vazão de água no interior de túneis, definindo suas rotas ao longo da encosta através das estruturas de abatimento. Os resultados obtidos mostram o papel da água de escoamento superficial e subsuperficial na evolução das formas erosivas associadas ao processo de erosão em túneis, com destaque para as estruturas de abatimento, depressões na superfície do terreno e o próprio túnel. As estruturas de abatimento evidenciam a existência de canais subsuperficiais em baixa encosta, alinhadas e com fluxo constante, geradas pela infiltração e exfiltração de água presente no solo após eventos chuvosos. Esses túneis possuem uma vazão rápida com presença de artesianismo na parte mais baixa da encosta onde há fluxo de retorno, constatando-se que esse sistema de túneis tem um importante papel na drenagem da encosta.
\end{abstract}

Palavras-chave: Erosão em túnel. Estimativa de vazão. Estrutura de abatimento.

Resumen: La formación de túneles evidencia directamente relacionada a la infiltración y la percolación de agua en la ladera. El agua que se infiltra en el suelo, naturalmente, tiende a seguir el camino hacia la gravedad, de acuerdo con la energía potencial adquirida por la inclinación de la pendiente. el propósito de este estudio fue reconocer el flujo de agua en el interior de túneles que definen sus rutas a lo largo de la ladera a 
través de las estructuras de disminuir. los resultados mostraron el papel de la escorrentía del agua del subsuelo y la evolución de formas asociadas con el proceso erosivo de la erosión en los túneles, especialmente las estructuras de depresiones hundimientos en la superficie de la tierra y el propio túnel. Las estructuras de descuentos muestran la existencia de canales subterráneos de baja pendiente, alineados y el flujo constante generada por la infiltración y exfiltración de agua presente en el suelo después de los eventos de lluvia. Estos túneles tienen un flujo rápido con la presencia de artesianismo en la parte inferior de la pendiente donde hay flujo de retorno, señalando que este sistema de túnel tiene un papel importante en el drenaje de la pendiente.

Palabras clave: Túnel de erosión. Flujo estimado. La estructura de disminuir.

\begin{abstract}
The formation of tunnels evidences the direct relation with infiltration and percolation of water into the slope. The water that infiltrates the soil naturally tends to follow the path in favor of gravity, according to the potential energy gained by the steepness of the slope. The purpose of this study was to recognize the flow of water inside tunnels, defining their routes along the hillside through the structures of abatement. The results showed the role of runoff and subsurface water in the evolution of erosion forms associated with this process in tunnels, especially for structures of subsidence, depressions in the ground surface and the tunnel itself. The abatement structures show evidence of subsurface channels in lower slopes, lined and with steady flow, generated by the infiltration and exfiltration of water present in the soil after rainfall events. These tunnels have a fast flow with presence of artesianism in the lower part of the slope, where return flow exists, noting that this tunnel system has an important role in the drainage of the slope.
\end{abstract}

Keywords: Tunnel erosion. Estimation of flow. Structure of subsidence.

\title{
INTRODUÇÃO
}

A água é um dos principais elementos físicos da paisagem terrestre, interligando fenômenos da atmosfera inferior e da litosfera, agindo assim na modelagem e esculturação do relevo, e também no intemperismo das rochas e gênese das camadas pedológicas (COELHO NETTO, 1994). Conforme Karmann (2003), sua concentração no sistema Terra refere-se à hidrosfera, que perfaz o espaço desde a atmosfera até uma profundidade de 10 $\mathrm{km}$ abaixo da superfície da crosta terrestre. Nesse espaço ocorre a circulação da água em seus diferentes estados (sólido, gasoso e líquido). A esse processo de circulação dá-se o nome de ciclo da água ou ciclo hidrológico. Basicamente o ciclo hidrológico inicia-se com a evaporação das águas dos mares, rios e lagos e com a evapotranspiração, formando as nuvens, que precipitam sob a forma de chuvas. Ao atingir o solo, parte das águas infiltra-se, abastecendo os aquíferos, enquanto outra parte escoa para os rios, lagos e mares, onde todo o ciclo recomeça.

Existem entraves naturais para a precipitação da água da atmosfera para o solo, sendo o ar e os vegetais os principais deles, que impedem que ela venha com uma energia potencial elevada para a superfície. Se o solo estiver desprotegido de vegetação, juntamente com fatores como a declividade, quantidade de chuva, tempo de precipitação, 
umidade e composição, dá-se origem a processos erosivos de grande escala. Segundo Bertoni \& Lombardi (1990, p. 68), a erosão:

é o processo de desprendimento e arraste acelerado das partículas do solo causado principalmente pela água [...], as enxurradas, provenientes das águas de chuva que não ficaram retidas sobre a superfície, ou não se infiltraram, transportam partículas de solo[...].

Guerra e Guerra (2001) referem-se a esse processo como erosão pluvial, justamente em razão de a característica fundamental do processo ser a água da chuva. Os processos de erosão do solo se caracterizam como processos de degradação e instabilidade do ambiente que podem atingir várias proporções, destruindo a terra e seu valor agrícola através da erosão laminar, em sulcos, ravinas ou voçorocas e erosão em túneis (CAMARGO; CAMARGO FILHO; MASCARELLO, 2004). Essas formas de erosão podem constituir um processo natural de evolução geomorfológica decorrente da expansão da rede de drenagem sob as condições climáticas e hidrológicas atuais (OLIVEIRA, 1996).

A presente pesquisa visa reconhecer a dinâmica da água que chega e escoa por túneis e identificar como se opera esse processo de erosão. Nesse sentido, dar-se-á ênfase ao comportamento da água na encosta, sobretudo em relação às características de infiltração e escoamento subsuperficial, na gênese e evolução dos túneis.

Entende-se por túneis a abertura de canais em subsuperfície que variam de poucos centímetros a alguns metros, gerados por processos geoquímicos e hidráulicos que resultam no carreamento de minerais e partículas do solo (SELBY, 1994; GUERRA, 1994; GUERRA \& GUERRA, 2001). Eles resultam da exfiltração de água, gerando uma força associada a um gradiente de potencial hidráulico que atua sobre um grão ou sobre um grande volume de rocha/ solo (FERNANDES, 1990). É uma forma específica de erosão subsuperficial, que foi descrita pela primeira vez por Richthofen, em 1872, na China (ZACHAR, 1982).

Para Selby (1982) os fatores possíveis para o surgimento da erosão em túneis são: oscilações na precipitação, solo propenso ao surgimento de gretas de contração em períodos de seca, redução na cobertura vegetal, camada relativamente impermeável no perfil, existência de gradiente hidráulico e camada dispersiva no solo.

Os túneis constituem importantes vias de circulação de água em subsuperfície e podem entrar em colapso gerando sulcos no solo (SELBY, 1982), sendo o colapso do teto do túnel e o posterior voçorocamento do solo o estágio final da erosão em túneis (ZACHAR, 1982). Estudos realizados por Camargo (1998) no Segundo Planalto Paranaense confirmam esse afirmação, indicando que os túneis encontrados na região passam a constituir rotas preferenciais do fluxo de água e são responsáveis por diversos mecanismos de erosão que eventualmente evoluem para canais em superfície.

Essa forma de erosão também pode ser atribuída a fluxos concentrados através de macroporos no solo, fendas de dissecação ou fraturas nas rochas (ROMERO DÍAZ et al., 2007). É considerado como um processo limitado a determinados tipos de materiais, particularmente em regiões áridas (BRYAN \& JONES, 1997), tendo uma maior ocorrência em solos arenosos e argilosos (RICHLEY, 2000). Silva et al. (2012) explicam que coberturas 
superficiais gibbsíticas têm maior favorabilidade a agregação aumentando desse modo a permeabilidade e a porosidade de seus materiais e, consequentemente, o surgimento de canais em subsuperfície.

Portanto, o processo de formação dos túneis tem relação diretamente proporcional com os processos de infiltração e percolação de água no solo. Entende-se por infiltração o movimento de entrada de água no solo e percolação, o movimento da água pela força da gravidade dentro do solo. A água que infiltra no solo tende naturalmente a percorrer o caminho favorecido pela da gravidade, de acordo com a energia potencial adquirida pela declividade da encosta.

\section{ÁREA DE ESTUDO}

No município de Guarapuava, Paraná, afloram rochas vulcânicas ácidas e básicas da Formação Serra Geral, ocorrendo, no domínio das ácidas, os tipos dacitos, latitos, quartzo-latitos, riodacitos e riolitos, e no domínio das básicas, os basaltos maciços de natureza hipocristalina e tabular e derrames simples (TRATZ, 2009).

A área de estudos está inserida na bacia do Rio das Pedras (Figura 1), situada na unidade litoestratigráfica de basalto tabular maciço e na unidade de planalto dissecado, apresentando grande densidade de falhas e fraturas, que são aproveitadas pela rede de drenagem, configurando vales em forma de " $v$ " (TRATZ, 2009). Na sub-bacia do Rio das Pombas, bacia do Rio das Pedras, afloram basaltos tabulares maciços (JKSG-2) caracterizados por apresentar textura equigranular fina com coloração que varia do cinza ao cinza-escuro. Mineralogicamente são compostos, em média, por $45 \%$ de plagioclásio (hábito tabular), $45 \%$ de clinopiroxênio (cristais prismáticos), $5 \%$ de óxidos de ferro e $5 \%$ de clorita como mineral secundário (TRATZ, 2009).

Em campo observa-se o predomínio de estrutura amidolaidal nos afloramentos rochosos da alta e média encosta. Na baixa encosta não se observa essa característica, uma vez que os afloramentos mostram-se com características de textura maciça.

A cobertura pedológica da bacia é marcada pela presença de cambissolos húmicos alumínicos (CHa 6) e hálpicos distróficos (Cxbd 30), neosolos litólicos distroúmbricos (RLdh) e regolíticos húmicos (RRh 1), bem como nitossolos (Nbd 2) e latossolos LBd 2), ambos distróficos (SANTOS et al., 2006), predominando, segundo Müller \& Pott (2004), as classes dos latossolos e nitossolos.

Segundo classificação de Köppen, o clima da região é do tipo Cfb - subtropical mesotérmico -, úmido sem estação seca, com verões frescos e inverno moderado. A pluviosidade apresenta-se bem distribuída ao longo do ano, com precipitações médias anuais em torno de $1961 \mathrm{~mm}$, apresentando variações extremas consideráveis.

A vegetação natural da região, segundo Silva (2004), corresponde à Floresta Ombrófila Mista (FOM), sendo que atualmente o setor médio da encosta apresenta-se desmatado e com presença de pastagem para animais de pequeno e médio porte. No setor de baixa encosta, a margem direita do Rio das Pombas, onde aparece o processo erosivo em túneis, há presença 
de mata secundária composta por árvores de médio porte, com troncos finos e tortuosos, forrada por gramíneas e por plantas rasteiras adaptadas a solos com umidade constante.

Figura 1 - Localização dos túneis na encosta do Rio das Pombas (área de estudo)

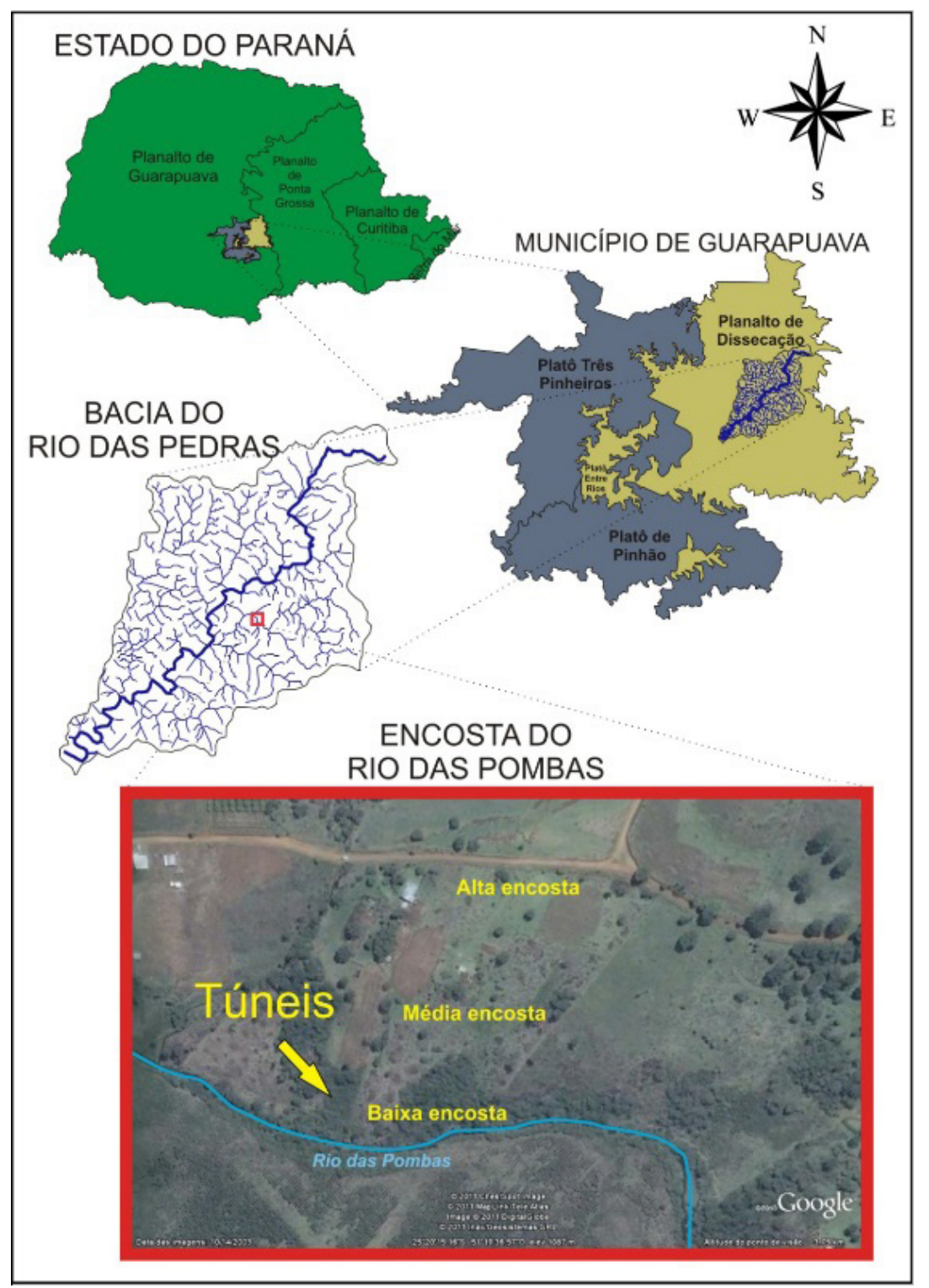

Fonte: Google Earth (2003), TRATZ, Eliza B. (2009) . Org.: Wellington Barbosa da Silva

\section{METODOLOGIA}

O presente trabalho buscou reconhecer o comportamento da água em cobertura superficial afetada por erosão em túneis, concentrando-se inicialmente no cadastramento das formas erosivas e na aplicação de experimentos que indiquem a ligação dos túneis encontrados na encosta, além da medição da vazão de água na saída dos túneis. Para tais experimentos, foram aplicadas as seguintes técnicas: 


\section{RECONHECIMENTO DO COMPORTAMENTO DA ÁGUA QUE CIRCULA DENTRO DOS TÚNEIS}

Para a compreensão dos processos de circulação da água dentro dos túneis, foram utilizados métodos simples para determinar a ligação entre os canais subsuperficiais, reconhecendo as entradas com grande fluxo, locais com maior exfiltração (laterais e teto) e as saídas com o fluxo concentrado.

Nesse experimento foram utilizados corantes de óxido de ferro e azul de metileno. Os testes foram efetuados em etapas diferentes para que não houvesse mistura entre os corantes e para verificação de resposta de cada um deles, sendo realizados por meio de aberturas na superfície, conhecidas como estruturas de abatimento, originadas pela subsidência do solo situado acima do teto dos túneis que posteriormente é levado pela água, sendo que foram avaliadas a fluidez das águas dentro dos canais e a ligação entre eles. A velocidade do fluxo de água no túnel poderá ser estimada através de materiais flutuadores ou dispersantes (corantes óxido de ferro ou azul de metileno) lançados em um ponto do túnel e por cronometragem do tempo de deslocamento desse ponto a outro. A estimativa vem sendo efetuada sob condições hidrológicas distintas.

\section{ESTIMATIVA DE VAZÃO DE ÁGUA NOS TÚNEIS}

Buscando a menor interferência possível no sistema de túneis, a vazão é estimada pelo método da velocidade, através da construção de seções ao longo do canal por onde a água oriunda dos túneis escoa superficialmente de forma concentrada.

A construção das seções é feita estabelecendo-se alguns critérios básicos para uma melhor e mais fácil coleta dos dados. Primeiramente foram colocados quatro specks (com $50 \mathrm{~cm}$ de comprimento) ao longo do canal de fluxo concentrado em distâncias de 0,5 m nos três primeiros specks e $1 \mathrm{~m}$ do terceiro para o último speck.

Os testes para a medição de vazão foram realizados utilizando-se o corante azul de metileno, pelo fato desse tipo de corante ter cor contrastante com o solo e por não oferecer prejuízos à vida de insetos e pequenos animais que vivem ou se utilizam dos túneis para se refugiarem, não interferindo assim de forma alguma na evolução natural dos canais.

\section{REGISTRO FOTOGRÁFICO}

A observação e análise dos túneis também foram efetuadas através de fotografias tiradas nas estruturas de abatimento. Trata-se de fotografias digitais tiradas com Câmera Cânon A530 onde as estruturas de abatimento permitiam acesso, já que suas aberturas possuem um pequeno diâmetro, assim como os túneis. Por esses fatos, não foi possível usar escalas padronizadas. No entanto, com o auxílio das fotografias foi possível observar e analisar mecanismos específicos aos túneis, em lugares onde o olho humano não teria acesso. 


\section{RESULTADOS E DISCUSSÕES}

A encosta em estudo caracteriza-se por apresentar-se como uma rampa longa, com declividade baixa $(<10 \%)$ nos setores alto e médio, e declividades mais elevadas $(>10 \%)$ na sua porção inferior. Quanto ao uso da encosta, as porções alta e média são ocupadas por pastagem e somente a baixa encosta apresenta mata secundária composta de árvores de médio porte com troncos finos e tortuosos, forrada de gramíneas e plantas rasteiras típicas de lugares com umidade constante.

Nota-se rápida decomposição de matéria orgânica no local e presença de uma fina camada de serrapilheira. Nessa porção da encosta é que se desenvolve o sistema de túneis. Através de sondagens realizadas com trado holandês, observou-se que o solo não ultrapassa $1,5 \mathrm{~m}$, além disso, em áreas limítrofes à mata, observou-se a ocorrência de afloramento de blocos rochosos densamente fraturados em planos ortogonais bem definidos.

\section{DISTRIBUIÇÃO, CARACTERIZAÇÃO DE TÚNEIS E FEIÇÕES ASSOCIADAS SITUADAS EM BAIXA ENCOSTA}

No setor de baixa encosta do Rio das Pombas registra-se erosão subsuperficial em túneis, onde se destaca a presença de estruturas de abatimento e subsidência do teto dos túneis, que são feições materializadas na superfície e que revelam o estágio em que um sistema de túneis se encontra.

São encontradas feições típicas (estruturas de abatimento, subsidência do teto do túnel, etc.) dessa forma de erosão, evidenciando dois sistemas de túneis independentes na encosta. Um sistema se apresenta com todas as feições superficiais e subsuperficiais e outro com apenas feições subsuperficiais, uma estrutura de abatimento e uma pequena ravina na zona de exfiltração de água da encosta.

As feições superficiais desse processo erosivo demonstram três estágios de evolução nos sistemas encontrados na baixa encosta. São eles: a) subsidência do teto do túnel; b) estrutura de abatimento; e c) incisão (sulco, ravina ou voçoroca).

$\mathrm{Na}$ encosta, a disposição aproximada das estruturas de abatimento, bem como a zona de exfiltração de água, as ravinas, a subsidência do teto do túnel e as trincheiras abertas podem ser visualizadas na Figura 2. Nesse setor, a encosta se apresenta com formato côncavo convexo com baixa declividade e cobertura superficial rasa, não ultrapassando $0,98 \mathrm{~m}$ de profundidade.

Para a determinação da ligação entre os túneis, foi lançado corante azul de metileno nas estruturas de abatimento que apresentavam fluxo subsuperficial concentrado. Nesse teste foi observado que uma das estruturas de abatimento, que também apresentava fluxo concentrado, não tinha ligação com as demais, sugerindo assim a existência de dois sistemas independentes na encosta (sistema 1 e sistema 2). 
Figura 2 - Distribuição das estruturas de abatimento e trincheiras abertas na encosta

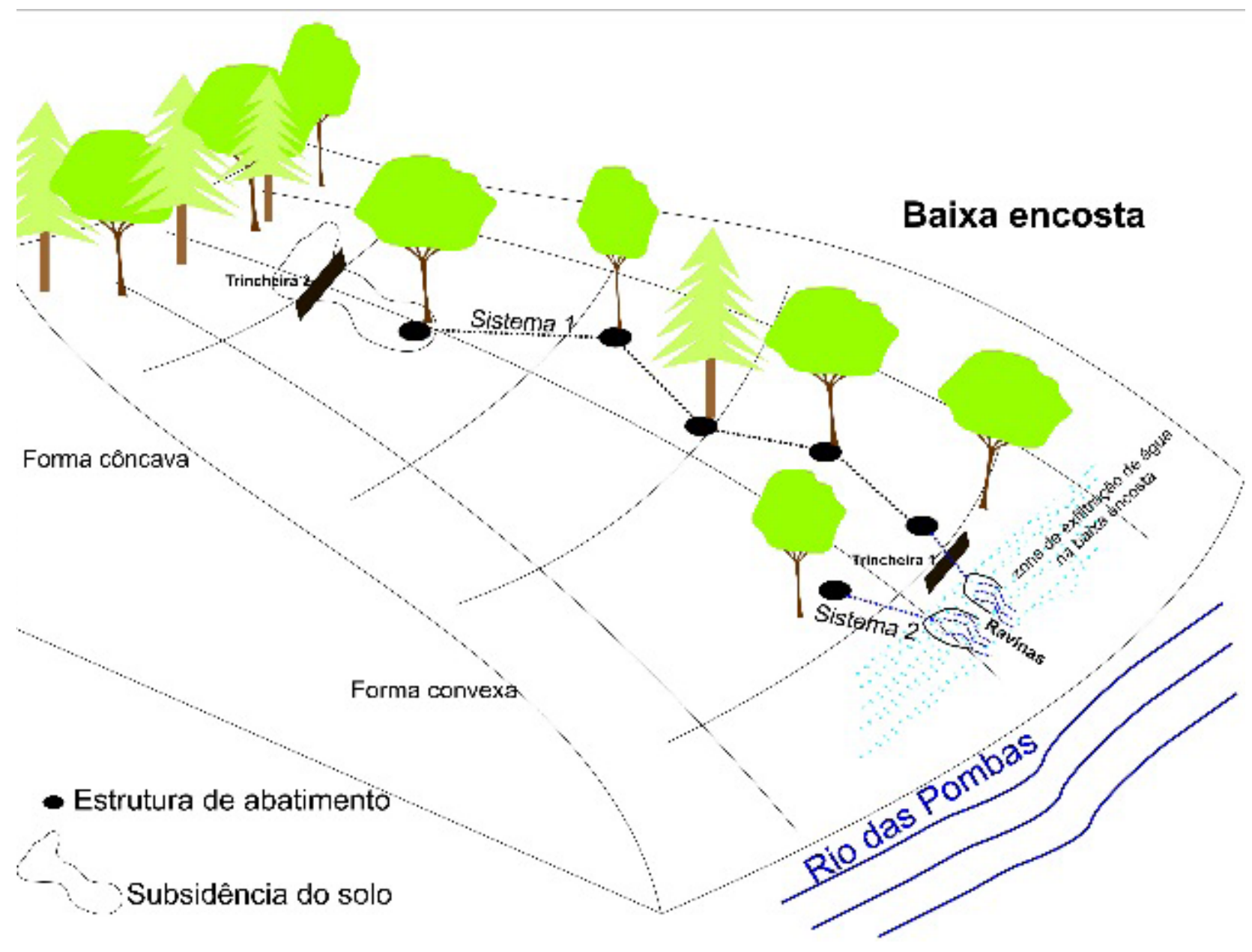

Org.: Autor

A evolução desses sistemas de túneis se dá principalmente pela ação do movimento da água dentro do solo (fluxos concentrados, exfiltração e liquefação), apresentando como mecanismos secundários de evolução a perturbação de animais e plantas. De acordo com a posição das estruturas de abatimento, notou-se que os túneis não obedecem necessariamente à topografia da encosta. Nem sempre a forma da encosta interfere no direcionamento dos fluxos em subsuperfície, já que os túneis causam alívio de pressão dentro do material, atraindo os fluxos para si. Portanto, a forma convexa conferida à parte final da baixa encosta não altera a direção dos fluxos subsuperficiais.

Só há alteração nos fluxos subsuperficiais quando há também alteração na topografia da encosta causada pela subsidência do teto do túnel, somada à estrutura de abatimento, o que condiciona os fluxos superficiais a entrarem nos túneis. Essa alteração na topografia da encosta é localizada somente em um ponto da baixa encosta, onde a subsidência do teto do túnel expôs lateralmente uma estrutura de abatimento (Figura 3), servindo dessa forma como ponto preferencial de entrada de fluxos superficiais. 
Figura 3 - Estrutura de abatimento exposta lateralmente devido à subsidência do teto do túnel

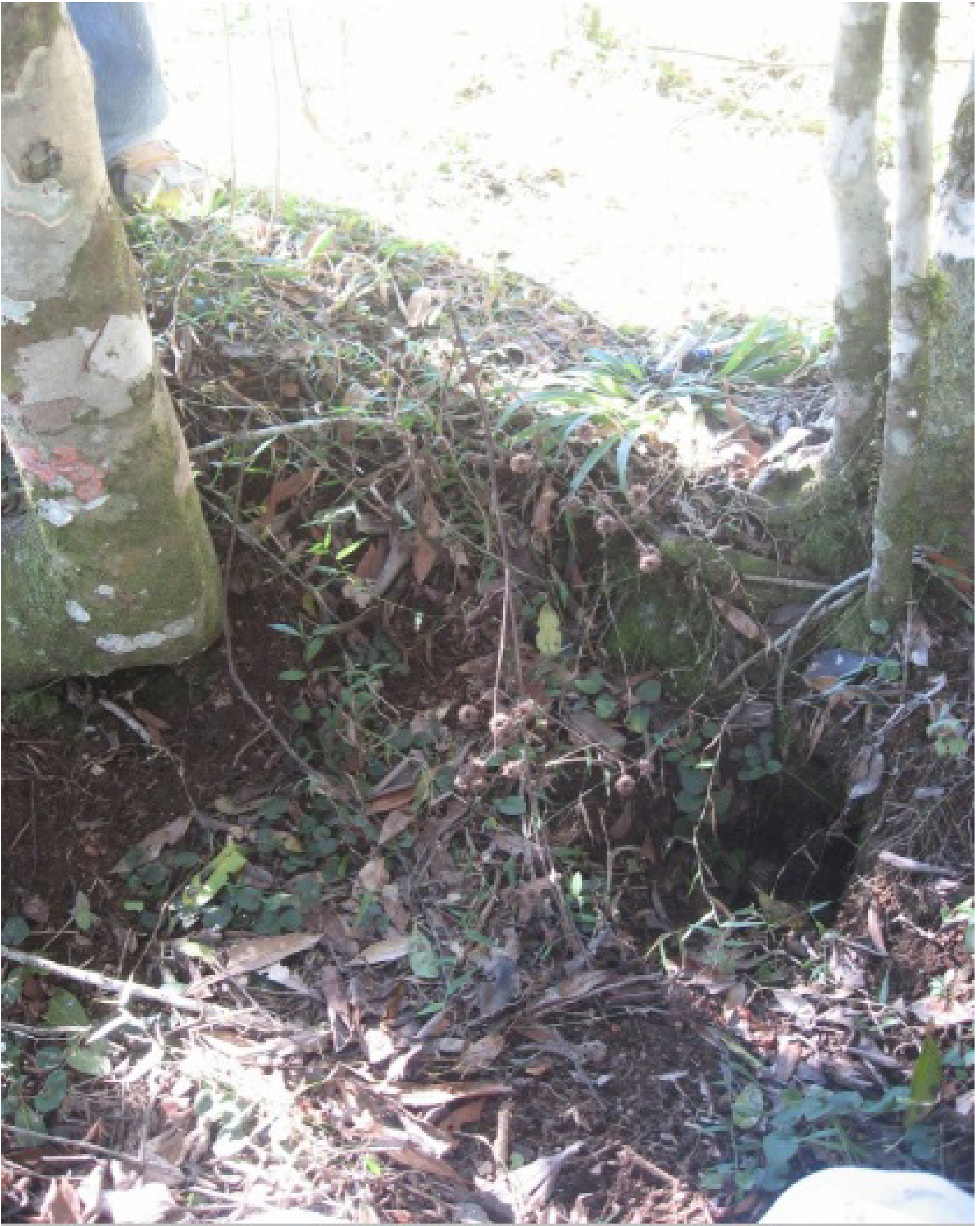

Foto: Wellington Barbosa da Silva 
A Figura 4 representa um quadro hipotético da distribuição e relação dos túneis, estruturas de abatimento e depressões geradas por subsidência que ocorrem na encosta, bem como a presença da água no sistema.

Figura 4 - Representação hipotética da distribuição e relação dos túneis, estruturas de abatimento e depressões geradas por subsidência que ocorrem na encosta.

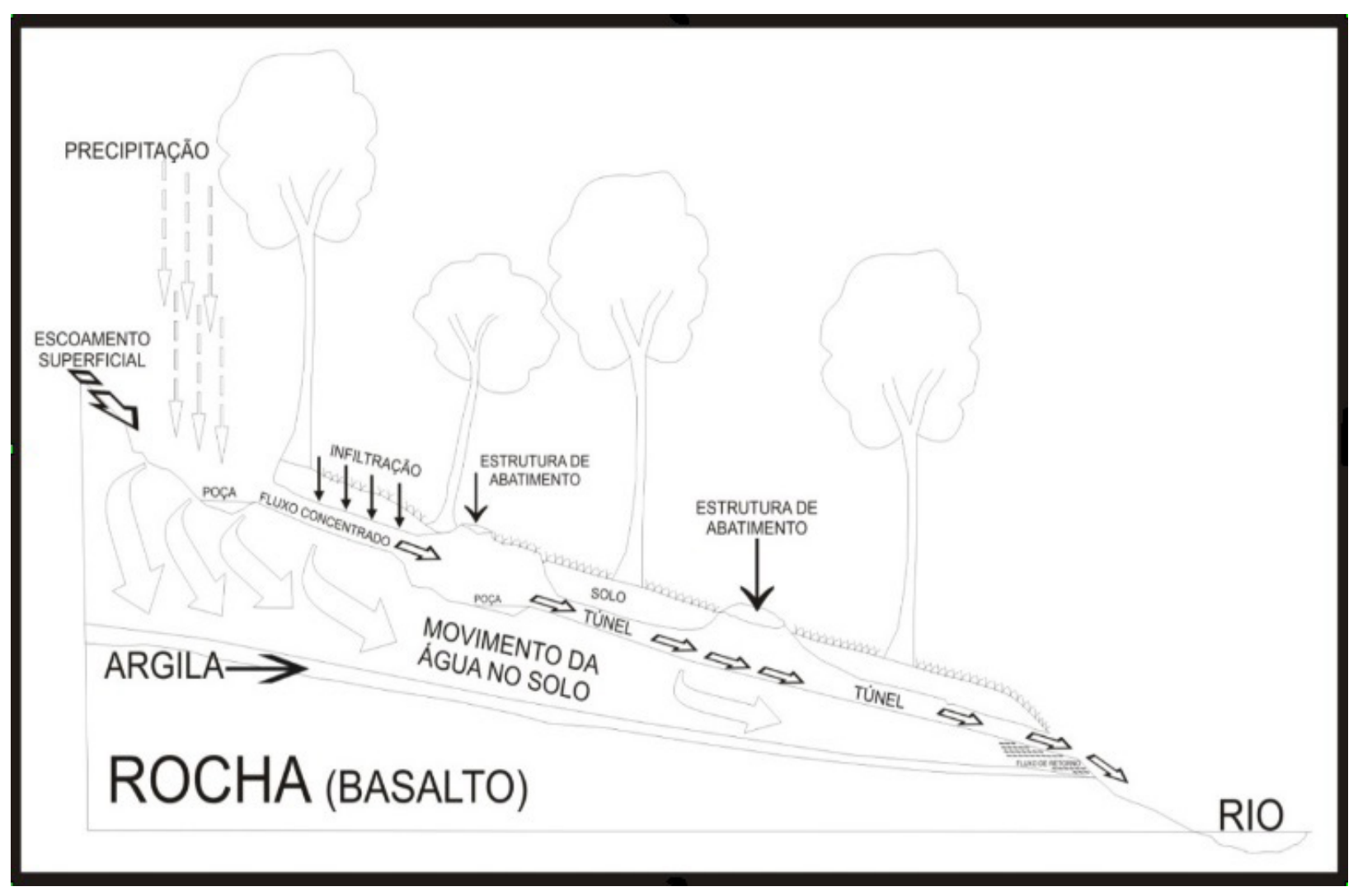

Nele pode-se observar o comportamento da água no solo a partir da depressão gerada pela subsidência do teto, redistribuindo a água no solo e direcionando o fluxo superficial durante uma precipitação para uma entrada lateral em relação à superfície. Essas depressões também são responsáveis por parte da serrapilheira que se encontra dentro dos túneis.

Já as estruturas de abatimento são aberturas em formato circular existentes na superfície da encosta geradas pelo desabamento de parte do teto, expondo os canais e as características de cada sistema de túneis, como acúmulo de água (poça) e formas erosivas de acordo com a energia da água em cada parte do trajeto (Figura 5). 
Figura 5 - Estrutura de abatimento em condições de artesianismo

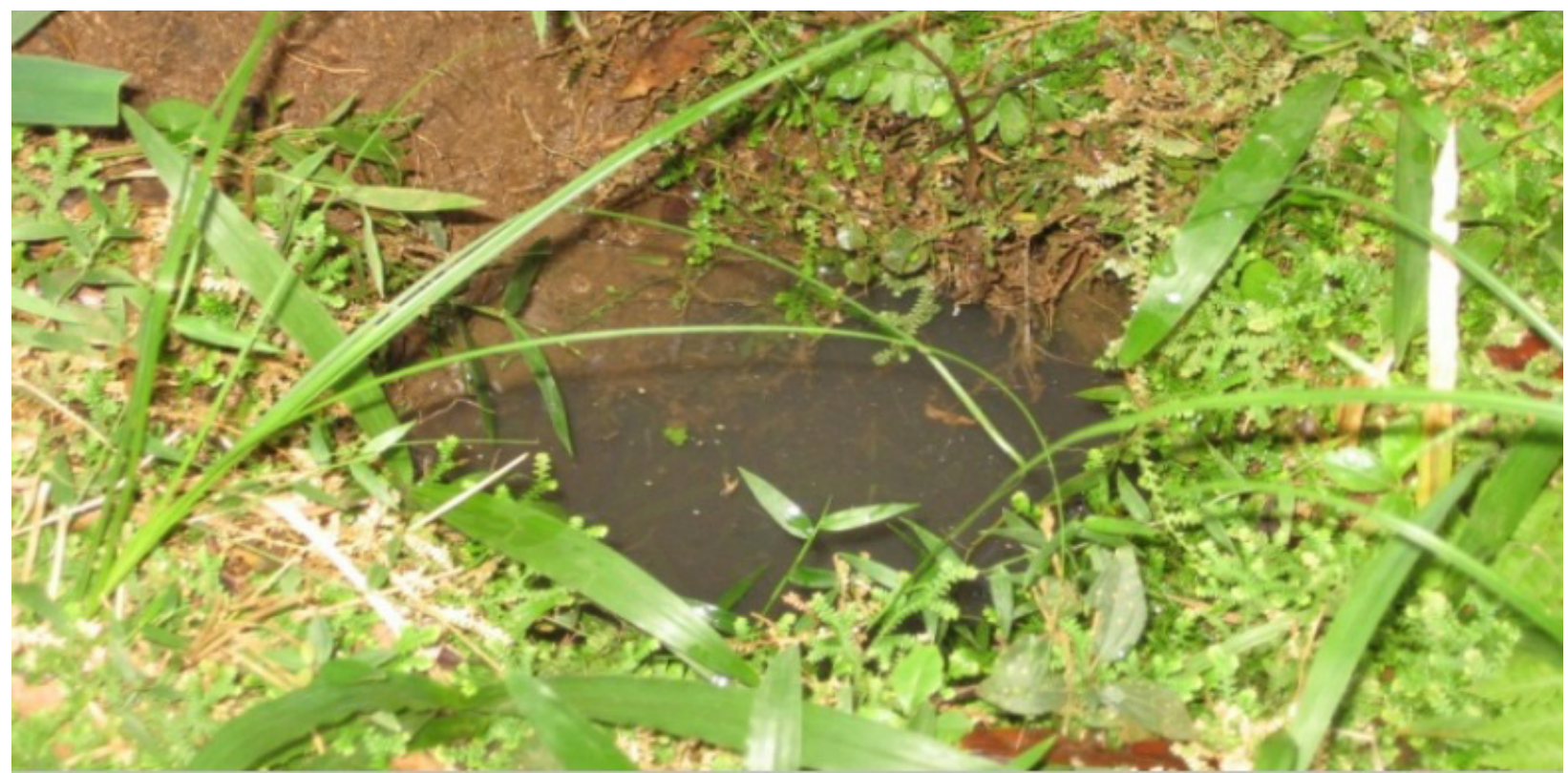

Foto: Wellington Barbosa da Silva

Também está exposta de forma simplificada a importante função das raízes das árvores e gramíneas na retenção de solo e estabilidade do teto dos túneis, que se encontram de 7 a $15 \mathrm{~cm}$ em média (Figura 6), imediatamente abaixo da superfície. Dentro dos túneis, a água circula de forma livre com o fluxo direcionado para a saída mais abaixo de um canal (fluxo concentrado).

Figura 6 - Raízes no teto do túnel e água acumulada na base do sistema de túneis.

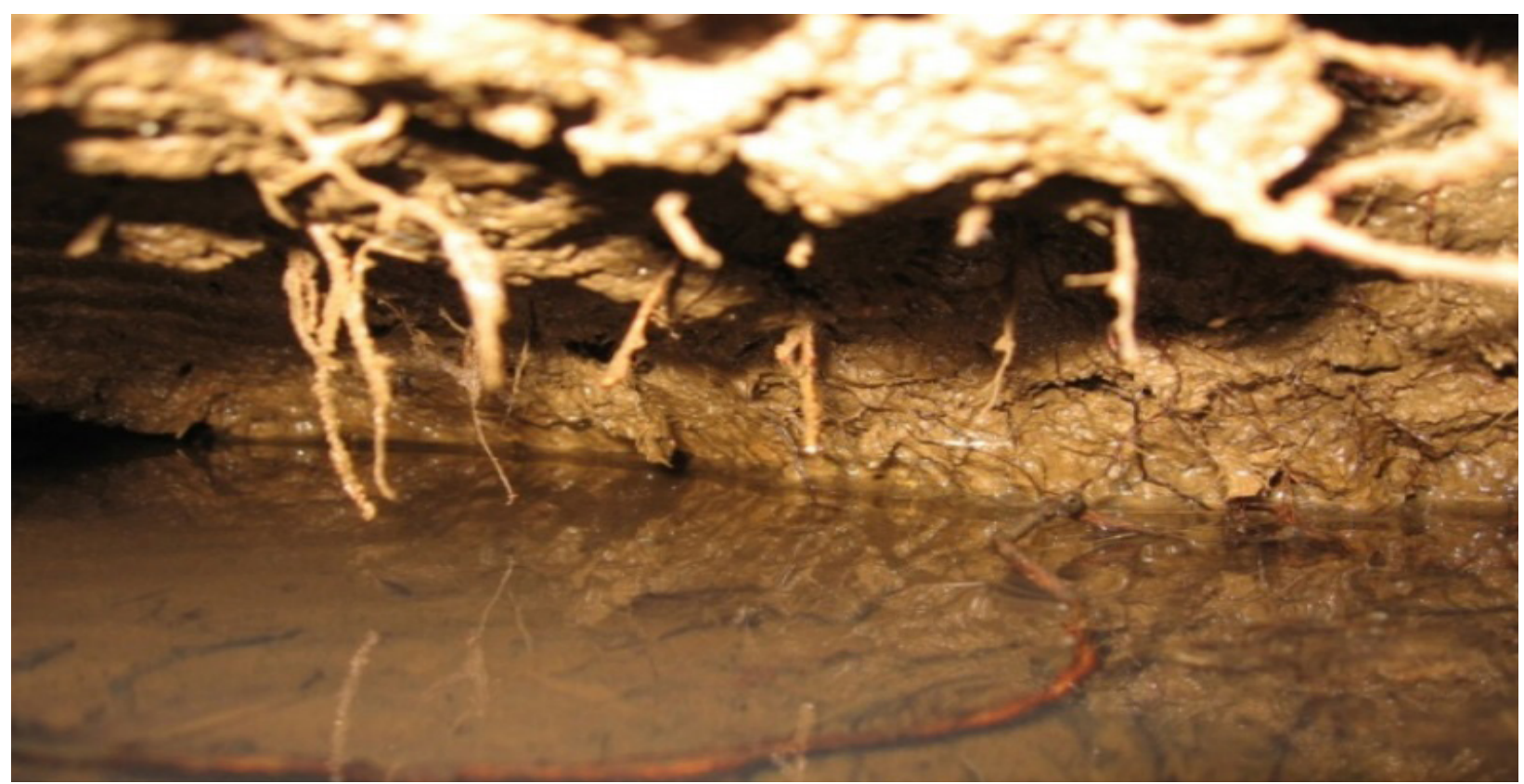

Foto: Wellington Barbosa da Silva 
A água que infiltra em toda a encosta e que não é canalizada pelo sistema de túneis movimenta-se respeitando a lei da gravidade, sendo exfiltrada no canal principal dos túneis próximo ao rio (fluxo de retorno). Os túneis apresentam, logo após as precipitações, um volume maior de água que exfiltra por suas paredes, dando a eles umidade constante, gerando fluxo concentrado a partir do maior aporte de água.

As estruturas de abatimento, que se localizam próximas ao setor da encosta onde ocorre fluxo de retorno, apresentam artesianismo sob condições de maior volume de precipitação. Após o rebaixamento do aquífero o que se observa no túnel é a presença de fungos visíveis pelo recobrimento de uma superfície branca descontínua nas paredes e teto do túnel (Figura 7).

Figura 7 - Fungos no teto e parede do túnel

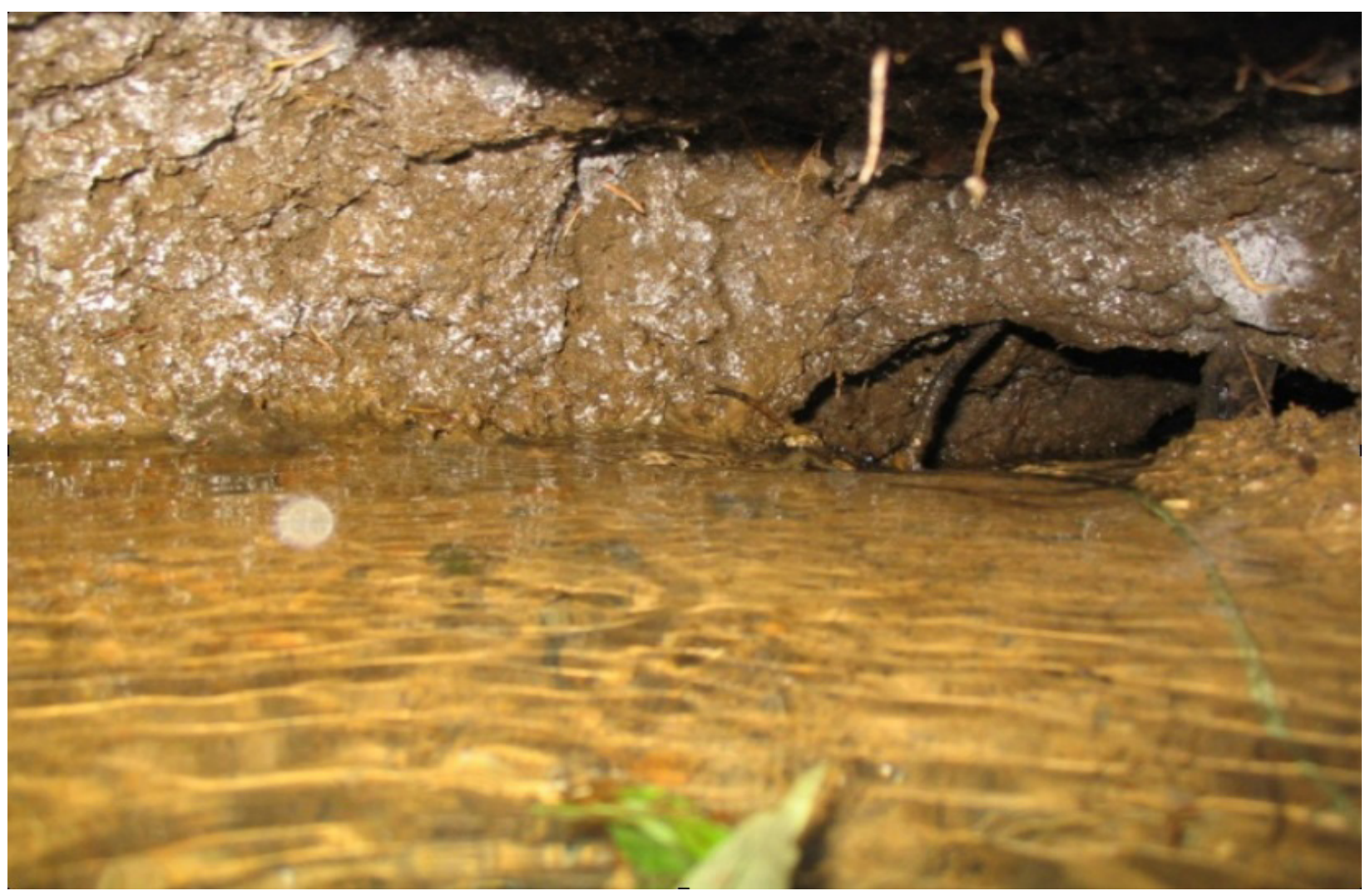

Foto: Wellington Barbosa da Silva

Na porção basal do túnel a ausência dessa superfície com fungo é interpretada com marca do nível da água que escoou pelo túnel e retirou a camada de fungos, sendo, portanto, um indicador da altura máxima da água no canal em determinadas condições de umidade.

A movimentação da água dentro dos canais destaca e transporta quantidades de sedimentos que variam em volume conforme a turbulência dos fluxos, que é dada pela quantidade de água no sistema versus o tempo. Quanto maior a quantidade de água no menor tempo, mais turbulento será o fluxo, transportando e depositando sedimentos 
destacados das paredes, do teto e de agregados presos às raízes das plantas localizadas acima do teto dos túneis. Muito dos sedimentos acumulados apresentam-se na forma de agregados de solo e não de partículas individuais (Figura 8).

De acordo com Castro (1999) agregado é um conjunto coerente de partículas primárias do solo com forma e tamanho definidos. Comporta-se, mecanicamente, como uma unidade estrutural. Segundo o mesmo autor, existem alguns fatores que produzem estruturas fragmentares; neste caso específico, os fatores que mais se encaixam com a situação do solo da área são: 1) a acumulação dos constituintes, devido à presença de matéria orgânica, atividade biológica, argila, ferro, calcário e sílica; 2) a quebra ou fissuração dos domínios floculados ou cimentados, devido às variações de volume relacionadas às oscilações no teor de umidade e presença de argilas expansíveis.

Figura 8 - Sedimentos acumulados no interior do túnel

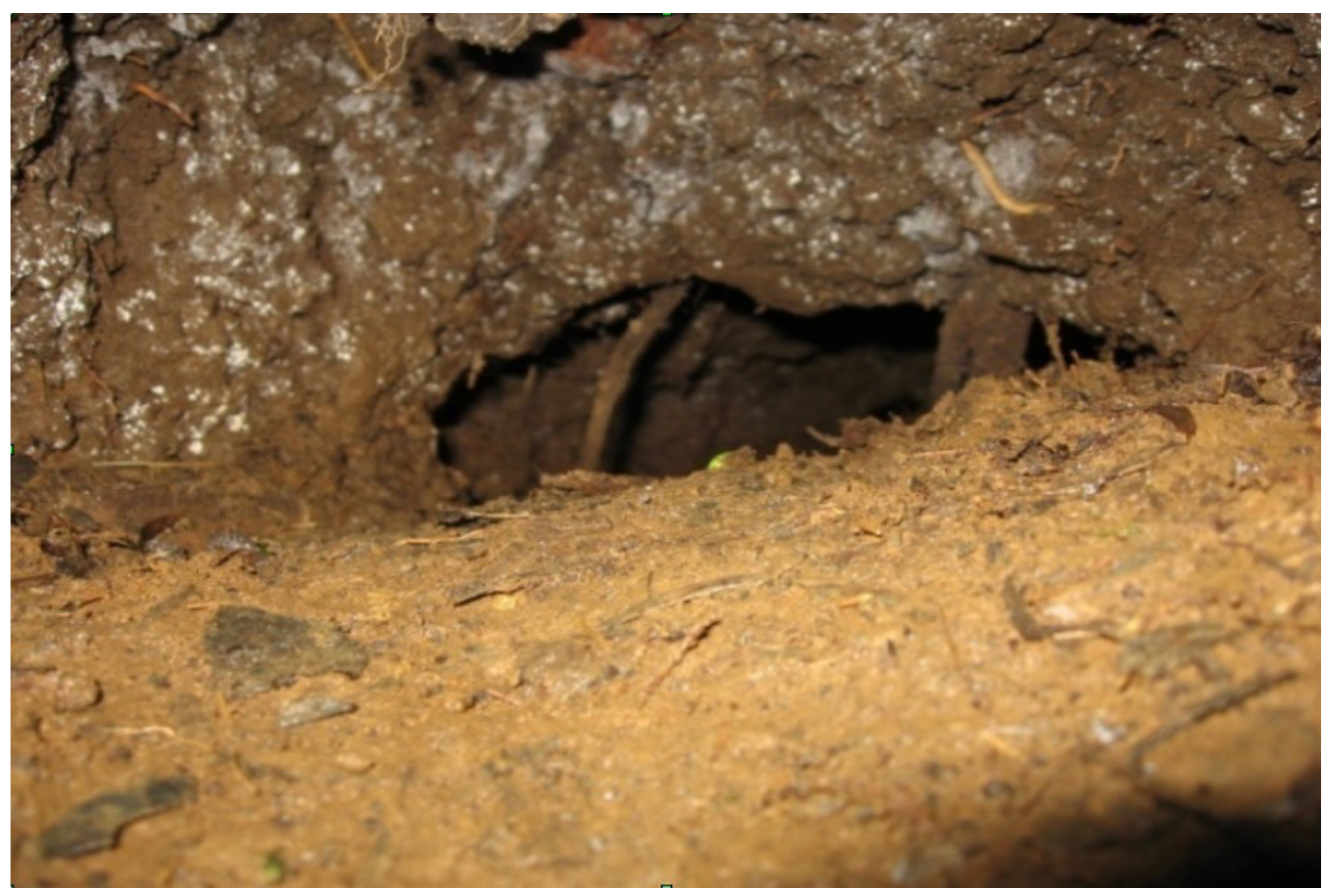

Foto: Wellington Barbosa da Silva

Devido à falta de material existente dentro dos túneis, o material que se encontra no teto dos canais, com grande quantidade de matéria orgânica e raízes, tende a ser erodido, descolando pequenos e médios grumos para a base dos canais (Figura 9), desestruturando assim os agregados, que caem e se acumulam na base do túnel, fazendo com que posteriormente esse teto perca sustentação e desabe, tornando-se uma estrutura de abatimento. 
Figura 9 - Agregados de solo desprendidos do teto do túnel e sedimentados na porção basal

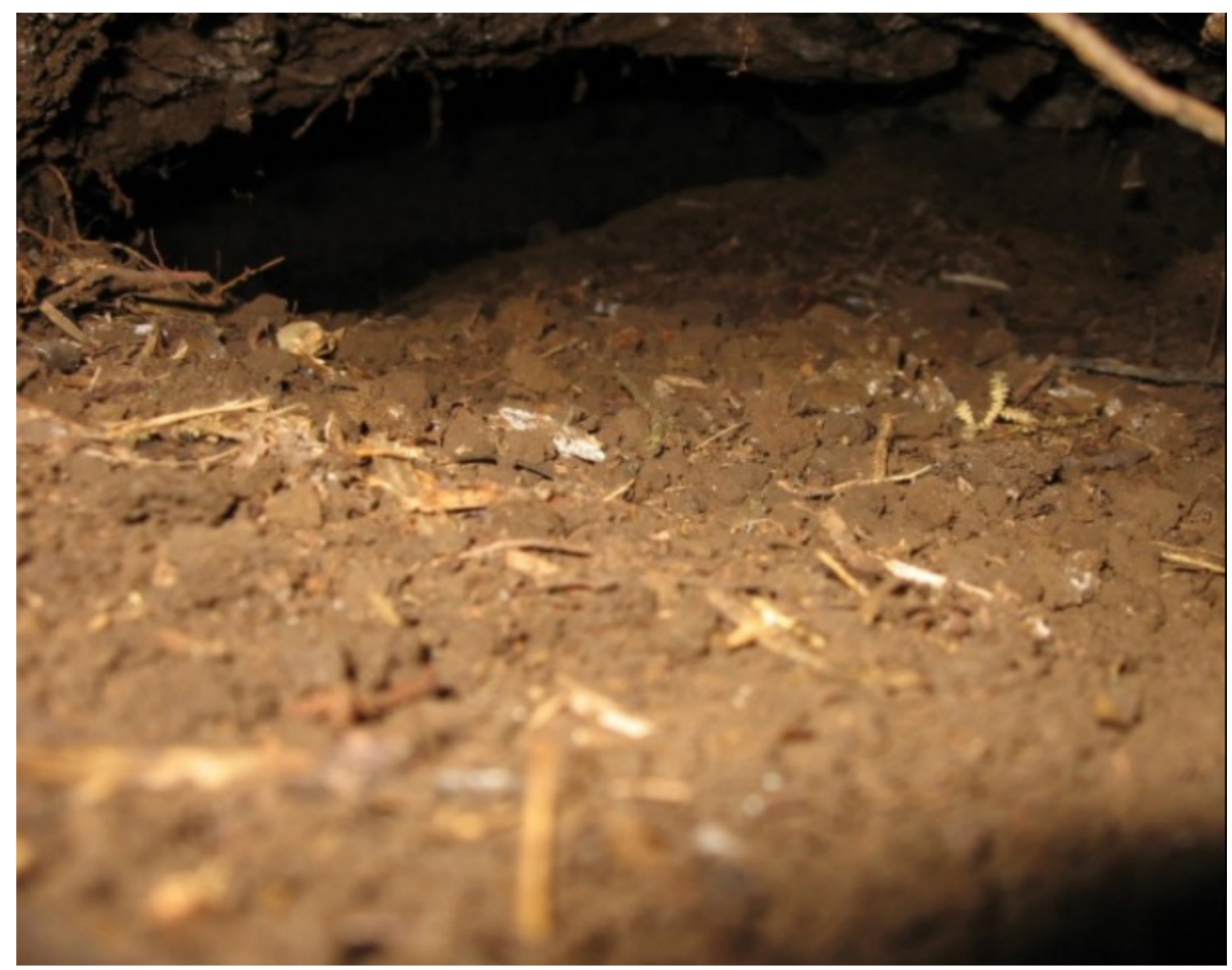

Foto: Wellington Barbosa da Silva

Os sedimentos soltos são carreados pelos canais para as partes mais baixas da encosta. A subsidência do teto tem papel fundamental na evolução dos canais, expondo partes dos túneis à superfície e favorecendo a entrada lateral de água do escoamento superficial. A maior subsidência do teto da área de estudo localiza-se na transição entre o campo aberto e a mata. Esta recebe uma quantidade muito grande de água superficial da parte superior da encosta, formando uma pequena bacia retentora de água e material orgânico (folhas e pequenos galhos), que, quando cessa a precipitação, fornece, por um curto período, água para a encosta. Essa depressão no terreno recebe o fluxo superficial da parte descoberta da encosta e faz diminuir a velocidade de entrada da água no primeiro duto, evitando assim um processo de erosão mais acelerado na parte mais alta da área de estudos. 


\section{ESTIMATIVA DE ROTA DE FLUXO E VAZÃO DE ÁGUA DOS TÚNEIS}

A rota do sistema de túneis presentes na encosta pode ser definida por meio da conexão entre estruturas de abatimento desde que haja fluxo constante de água por toda a extensão do túnel e pelo lançamento do corante azul de metileno, além da observação do aparecimento deste a jusante. Os parâmetros dimensionais e de velocidade levantados em seções do canal estão contidos na tabela 1.

Tabela 1 - Parâmetros dimensionais e de velocidade levantados em quatro seções do canal principal em 8/12/2006

\begin{tabular}{c|c|c|c|c}
\hline & $\begin{array}{c}\text { SEÇÃO 1 } \\
(0 \mathrm{CM})\end{array}$ & $\begin{array}{c}\text { SEÇÃO 2 } \\
(0-50 \mathrm{CM})\end{array}$ & $\begin{array}{c}\text { SEÇÃO 3 } \\
(50-100 \mathrm{CM})\end{array}$ & $\begin{array}{c}\text { SEÇÃO 4 } \\
(100-200 \mathrm{CM})\end{array}$ \\
\hline Profundidade & $2 \mathrm{~cm}$ & $1,5 \mathrm{~cm}$ & $2 \mathrm{~cm}$ & $1,5 \mathrm{~cm}$ \\
\hline Largura & $5 \mathrm{~cm}$ & $7 \mathrm{~cm}$ & $5 \mathrm{~cm}$ & $6 \mathrm{~cm}$ \\
\hline Tempo de percurso & $0 \mathrm{~s}$ & $7 \mathrm{~s}$ & $11 \mathrm{~s}$ & $57 \mathrm{~s}$ \\
\hline
\end{tabular}

O resultado obtido indica vazão $Q \cong 0,0015 \mathrm{~cm} / \mathrm{s}$ ou $0,000015 \mathrm{~m} / \mathrm{s}$. Deve-se considerar que o período que compreendeu a metade de novembro até a metade do mês de dezembro de 2006, foi de estiagem com esparsas chuvas concentradas (48 $\mathrm{mm}$ de precipitação no período de 30 dias antecedentes ao dia 8/12/2006). É importante destacar que toda a água presente nesse período, no fundo das aberturas dos túneis e a que estava sendo exfiltrada, era fruto da capacidade de armazenamento do solo de boa parte da encosta, e não apenas da área de estudo, mostrando assim a concentração do fluxo dentro do canal.

\section{CONCLUSÕES}

Os resultados obtidos evidenciam o papel da água de escoamento superficial e subsuperficial na evolução das formas erosivas associadas ao processo de erosão em túneis, com destaque para as estruturas de abatimento, depressões na superfície do terreno e o próprio túnel. As estruturas de abatimento mostram a existência de canais subsuperficiais em baixa encosta, alinhadas e com fluxo constante, geradas pela infiltração de água e posterior exfiltração em face exposta nas paredes e no teto dos túneis. Esses túneis possuem uma rápida vazão com presença de artesianismo na parte mais baixa da encosta onde há fluxo de retorno, constatando-se que esse sistema de túneis tem um importante papel na drenagem da encosta. 


\section{AGRADECIMENTOS}

À Capes, pelo apoio financeiro concedido durante a elaboração deste trabalho.

\section{REFERÊNCIAS}

BRYAN, R. B. \& JONES, J. A. A. The significance of soil piping process: inventory and prospect. Geomorphology 20, p. 209-218, 1997.

BERTONI, J.; LOMBARDI, F. N. Conservação do solo. 3.ed. São Paulo: Ícone, 1990.

CAMARGO, G. Processo de erosão no Centro e Sul do Segundo Planalto Paranaense: evolução de encosta e influência da erosão subterrânea na expansão de voçorocas. Dissertação de (Mestrado) - Universidade Federal de Santa Catarina, Florianópolis (SC), 1998.

.; CAMARGO FILHO, M.; MASCARELLO, L. V. Processos de erosão em ravinas e voçorocas na bacia do Rio das Pedras. In: BATTISTELLI, M.; CAMARGO FILHO, M.; HEERDT, B. (Orgs.). Proteção e manejo na bacia do Rio das Pedras: relato de experiências. Guarapuava: Ed. B\&D Ltda, , 2004.

CASTRO, S. S. Micromorfologia de solos aplicada ao diagnóstico de erosão. In: GUERRA, A. J. T.; SILVA, A. S da; BOTELLHO, R. G. M. (Orgs.). Erosão e conservação dos solos. Rio de Janeiro: Bertrand Brasil, 1999, p. 127-163.

COELHO NETTO, A. L. Hidrologia de encosta na interface com a Geomorfologia. In: GUERRA, A. J. T.; CUNHA, S. B. da (Orgs.). Geomorfologia: uma atualização de bases e conceitos. Rio de Janeiro: Bertrand Brasil, 1994.

FERNANDES, N. F. Hidrologia subsuperficial e propriedades físico-mecânicas dos "complexos de rampa"- Bananal (SP). Rio de Janeiro. Dissertação (Mestrado) - Universidade Federal do Rio de Janeiro, IG/UFRJ, p. 160, 1990.

GUERRA, A. J .T. Processos erosivos nas encostas. In: GUERRA, A. J. T.; CUNHA, S. B. da (Orgs.). Geomorfologia: uma atualização de bases e conceitos. Rio de Janeiro: Bertrand Brasil, 1994, p. 149-209.

GUERRA, A. T.; GUERRA, A.J.T. Novo dicionário geológico-geomorfológico. $2^{\mathrm{a}}$ ed. Rio de Janeiro: Bertrand Brasil, 2001. $625 \mathrm{p}$.

KARMANN, I. O ciclo da água, água subterrânea e sua ação geológica. In: TEIXEIRA, W. et.al. Decifrando a Terra. 2.ed. São Paulo: Oficina de Textos, 2003.

. Notas preliminares sobre clima, solos e vegetação do estado do Paraná. Arquivos de Biologia e tecnologia, Curitiba, v. 3, p. 99-200, 1948.

MAACK, R. Geografia física do estado do Paraná. Rio de Janeiro: José Olympio, 2002. 450 p.

MENDONÇA, F. de A. O clima e o planejamento urbano de cidades de porte médio e pequeno: proposição metodológica para estudo e sua aplicação à cidade de Londrina PR. Tese (Doutorado em Geografia) - Faculdade de Filosofia, Letras e Ciências Humanas da Universidade de São Paulo, São Paulo, 1994.

MONTEIRO, C. A. F. Clima. In: Geografia do Brasil: Região Sul. Rio de Janeiro, IBGE, v. 4, t. 1, p. 114-166, 1968.

MÜLLER, M. M. L. \& POTT, C. A. Cobertura pedológica na bacia do rio das Pedras, Guarapuava/PR. In: Proteção e Manejo na Bacia do Rio das Pedras: relato de experiências. BATTISTELLI, M.; CAMARGO FILHO, M.; HEERDT, B. (Org). Ed. B\&D Ltda, Guarapuava, 2004.

NIMER, E. Climatologia do Brasil. Rio de Janeiro: IBGE, 1989.

OLIVEIRA, M. A. T. \& CAMARGO, G. Integração de estruturas de abatimento e erosão por voçorocas. Sociedade e natureza, Uberlândia, n. 15, p. 117-120, 1996. 
PINTO, H. S; ALFONSI, R. R. Estimativa das temperaturas médias, máximas e mínimas mensais no estado do Paraná, em função de altitude e latitude. Caderno de Ciências da Terra, São Paulo, n. 52, 28 p, 1974.

RICHLEY, Lindsay. Treatment of tunnel erosion in Tasmania. Natural Resource Management, v. 3, n. 2, setembro de 2000.

ROMERO DÍAZ, A. et al. The causes of piping in a set of abandoned agricultural terraces in southeast Spain. Catena, 2007.

SANTOS, H.G. et al. Solos: atualização do mapa de solos do estado do Paraná. SIBCS, 2006.

SELBY, M. J. Hillslope materials \& processes. New York, Oxford University Press, 1982.

J. Hillslope sediment transport and deposition. In: PYE, K. (Ed.) Sediment transport and depositional processes. London: Blackwell Scientific Publications, 1994. 397 p.

SILVA, D.W. A vegetação da Bacia do Rio das Pedras. In: Proteção e Manejo na Bacia do Rio das Pedras: relato de experiências. BATTISTELLI, M.; CAMARGO FILHO, M.; HEERDT, B. (Org.). Ed. B\&D Ltda, Guarapuava (PR), 2004.

SILVA, W.B. et al. Propriedades físicas e químicas de cobertura superficial em encosta com erosão em túneis, Guarapuava, PR. Revista Ambiência, v. 8, n. 3, p. 879-894, 2012.

TRATZ, E.B. As rochas vulcânicas da província magmática do Paraná, suas características de relevo e sua utilização como recurso mineral no município de Guarapuava-PR. Dissertação (Mestrado em Geografia). Universidade Federal de Santa Catarina, Florianópolis (SC), 176 p., 2009.

ZACHAR, D. Soil Erosion. Bratislava: Elsevier Scientific Publishing Company, 1982.

Recebido em 13/10/2012

Aceito para publicação em 22/10/2013 